\title{
OP67
}

\section{INVESTIGATION OF HUMAN CENTRIC LIGHTING IN INDUSTRIAL ENVIRONMENT IN MULTIPLE ASPECTS - BIOLOGICAL EFFECT AND USERS' PREFERENCE \\ Dávid Noel Tóth et al.}

DOI 10.25039/x46.2019.OP67

from

CIE x046:2019

Proceedings

of the

29th CIE SESSION

Washington D.C., USA, June 14 - 22, 2019

(DOI 10.25039/x46.2019)

The paper has been presented at the 29th CIE Session, Washington D.C., USA, June 14-22, 2019. It has not been peer-reviewed by CIE.

(C) CIE 2019

All rights reserved. Unless otherwise specified, no part of this publication may be reproduced or utilized in any form or by any means, electronic or mechanical, including photocopying and microfilm, without permission in writing from CIE Central Bureau at the address below. Any mention of organizations or products does not imply endorsement by the CIE.

This paper is made available open access for individual use. However, in all other cases all rights are reserved unless explicit permission is sought from and given by the CIE.

CIE Central Bureau

Babenbergerstrasse 9

A-1010 Vienna

Austria

Tel.: +4317143187

e-mail: ciecb@cie.co.at

www.cie.co.at 


\title{
INVESTIGATION OF HUMAN CENTRIC LIGHTING IN INDUSTRIAL ENVIRONMENT IN MULTIPLE ASPECTS - BIOLOGICAL EFFECT AND USERS' PREFERENCE
}

\author{
Tóth, D.N. ${ }^{1}$, Szabó, F. ${ }^{1}$ \\ ${ }^{1}$ Light and Colour Science Research Laboratory, University of Pannonia, Veszprém, \\ HUNGARY \\ toth.david.noel@virt.uni-pannon.hu
}

DOI $10.25039 / \times 46.2019 .0 P 67$

\begin{abstract}
The goal of the study was to investigate the effects of human centric lighting on the users via both objective measurements and subjective questionnaires in a real working environment with the participation of industrial employees. During the experimental sessions, heartrate of the participants had been monitored and the questionnaires periodically had to be filled out, assessing the participants' experiences about the experimental lighting. The results of the statistical analyses of the questionnaires clearly show a connection between circadian effects of the human centric lighting's continuously changing light settings and the participants' subjective feeling of alertness and their preferences. The effect of lighting had been proven using objective measurements besides the questionnaires. A significant moderate correlation between the circadian effect and the heartrate changes had been shown. The moderate strength can be acknowledged to other factors which influence the heartrate.
\end{abstract}

Keywords: human centric lighting, case study, LED, heartrate monitoring, CIE S026:2018

\section{Introduction}

The human biological clock synchronizes with the periodicity of day and night through the presence of light. It determines the timing of the sleep cycle through biological mechanisms of the circadian system. Disruption of this timing has various possible negative impacts on health. In short term sleep disorders and insomnia had been reported (Figueiro, Overington, 2015), in long term it can even lead to depression and cancerous diseases (Chang et al., 2015). In the industrial field working in night shifts is common, workers of these shifts and windowless factory buildings are exposed to these health risks. By introducing human centric lighting (HCL) to industrial workplaces the health risks on the workers could be reduced.

The light-dark periods of the day are detected by the intrinsically photosensitive ganglion cells (ipRGC) in the retina which contain melanopsin photopigment (Berson, 2003). The neural signal of these cells transfers directly to the suprachiasmatic nucleus (SCN) in the hypothalamus. Through the pineal gland, the SCN controls the level of melatonin hormone in the blood.

Since the absorption maximum of melanopsin - and thus the sensitivity maximum of ipRGCs is between $460 \mathrm{~nm}$ and $480 \mathrm{~nm}$ (Brainard et al., 2001), spectrally tuneable luminaires containing this wavelength range can be used to achieve specific effects on the circadian system. Furthermore, radiation in this wavelength range should be taken into account during the design of light sources and self-luminous devices to avoid unwanted effects on users.

\section{Quantifying the circadian response}

To evaluate - and later analyse - the effect of light on the circadian system a measure is needed. For this purpose, circadian light (CL) (Rea et al., 2010), and the new metrics of the CIE S026:2018 (CIE, 2018) can be used. In case of the most common artificial light sources the spectral composition of the emitted light is nearly constant during its lifecycle, causing its effects on the circadian system to be constant as well. In contrary to this, daylight reaching Earth's surface - and the observer's retina - is constantly changing due to cloudiness, atmospheric conditions, and Earth's rotation. Due to these phenomena calculating the effect on 
the circadian system results in different numbers under different measurement conditions (Bellia et al., 2014).

\subsection{Circadian light: $C L, C L_{A}$}

This metric aims to model the response of the whole circadian system (melatonin suppression) to a retinal illumination of given intensity and spectral distribution with a single number. The resulting number $(C L)$ is a spectrally weighted variant of irradiation, measured in $\mathrm{W} / \mathrm{m}^{2}$. It has a special variant denoted as $C L_{A}$ which proportions the circadian response to the test source to the circadian response to a retinal illuminance of $1000 \mathrm{Ix}$ generated by a CIE A illuminant. During the initial evaluation of the results this metric had been used, and was later compared with the results using the new CIE S026 metric.

\subsection{CIE S026:2018}

In the new CIE standard, the metrics, spectral sensitivity functions and quantities for calculation of ipRGC-influenced responses to light had been standardized. The standard introduced a group of new metrics to describe $\alpha$-opic responses. These metrics describe the responses of the five different photoreceptors in context of ipRGC-influenced responses to light. After the publication of the CIE S026:2018 standard, the measurement results of the experiments presented in this paper had been re-evaluated, using the a-opic irradiance metrics, which are measured in $\mathrm{mW} / \mathrm{m}^{2}$.

\section{Custom HCL luminaires}

Preceding the case study, a custom human centric lighting solution had been developed for industrial use. The result of this development was a spectrally tuneable luminaire and an intelligent control unit which can provide continuous transitions between specific spectral distributions - "lighting cornerstones" - over a long period of time. This method ensures that users do not notice the continuous minimal changes in the lighting. The peak wavelength of the blue LEDs had been chosen to be in the maximal sensitivity range of the ipRGCs. To be able to achieve dynamically mixed white light, the other channels of the tuneable luminaires are composed of phosphor white, green and red LEDs.

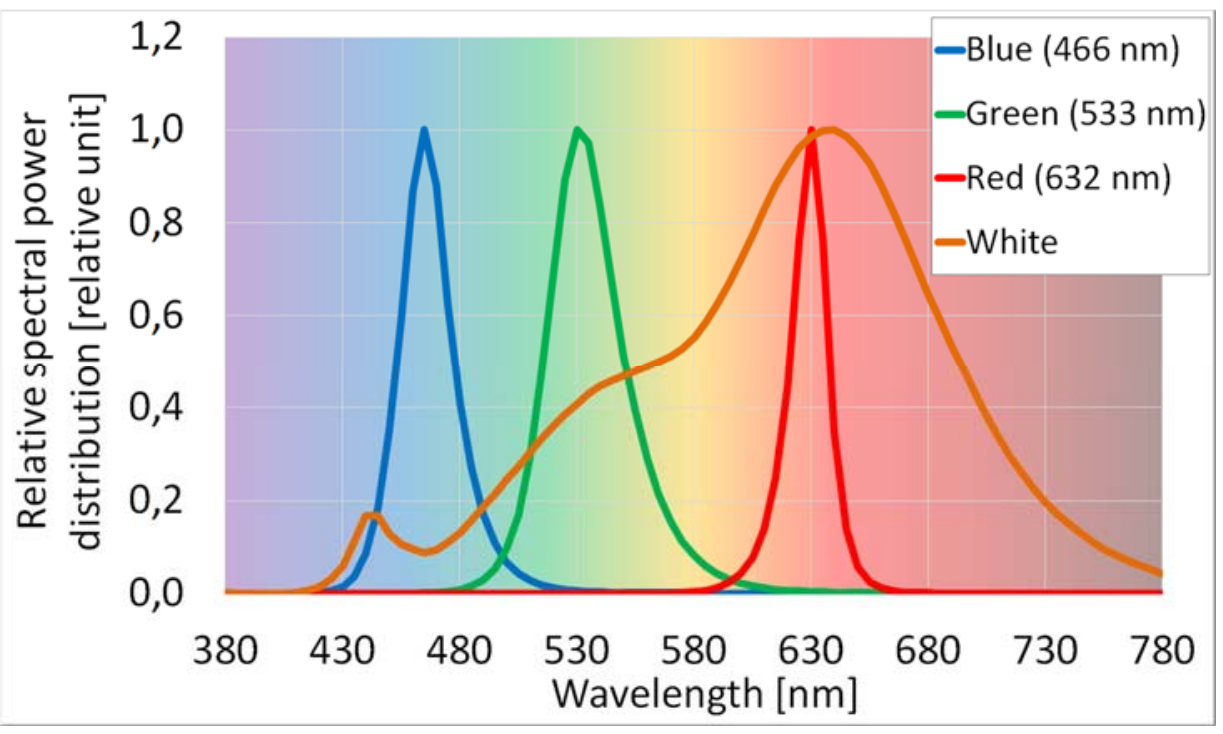

Figure 1 - LED channels of the tuneable luminaires

A series of the custom luminaires had been manufactured and installed in a real working environment: as local lighting at a workstation of an assembly line. The final settings of the built-in controller had been set on-site to be perfectly adapted to the environment. 
Table 1 - Photometric parameters of the light settings and the LED tube lighting used as comparison in the experiment, measured on the workplane

\begin{tabular}{|l|c|c|c|c|c|}
\hline \multicolumn{1}{|c|}{ Name } & $E_{\mathrm{v}}[\mathrm{Ix}]$ & $C C T[\mathrm{~K}]$ & $d_{\mathrm{uv}}$ & $R_{\mathrm{f}}$ & $R_{\mathrm{g}}$ \\
\hline "Stimulating" & 1300 & 6500 & 0,003 & 85 & 99 \\
\hline "Neutral" & 1000 & 4200 & $-0,002$ & 85 & 101 \\
\hline "Relaxing" & 750 & 3000 & 0,008 & 95 & 99 \\
\hline LED tube & 600 & 4214 & 0 & 90 & 98 \\
\hline
\end{tabular}

Table $2-C L_{A}$ and $\alpha$-opic irradiances of the light settings and the LED tube lighting system, measured at eye level

\begin{tabular}{|l|c|c|c|c|c|c|}
\hline \multicolumn{1}{|c|}{ Name } & $C L_{A}$ & $\begin{array}{c}\text { S-cone-opic } \\
{\left[\mathrm{mW} / \mathrm{m}^{2}\right]}\end{array}$ & $\begin{array}{c}\text { M-cone-opic } \\
{\left[\mathrm{mW} / \mathrm{m}^{2}\right]}\end{array}$ & $\begin{array}{c}\text { L-cone-opic } \\
{\left[\mathrm{mW} / \mathrm{m}^{2}\right]}\end{array}$ & $\begin{array}{c}\text { Rhodopic } \\
{\left[\mathrm{mW} / \mathrm{m}^{2}\right]}\end{array}$ & $\begin{array}{c}\text { Melanopic } \\
{\left[\mathrm{mW} / \mathrm{m}^{2}\right]}\end{array}$ \\
\hline "Stimulating" & 1210 & 503 & 954 & 1062 & 1001 & 933 \\
\hline "Neutral" & 520 & 254 & 665 & 821 & 606 & 531 \\
\hline "Relaxing" & 327 & 72 & 445 & 615 & 310 & 231 \\
\hline LED tube & 317 & 129 & 327 & 408 & 271 & 230 \\
\hline
\end{tabular}

During the spectral optimization of the light settings $C L_{A}$ had been used as the goal function, while CCT, $d_{\mathrm{uv}}, R_{\mathrm{f}}, R_{\mathrm{g}}$, and the maximal current allowed on each LED channel had been used as constraints. Two of the "cornerstones" had been chosen to have maximal ("stimulating") and minimal ("relaxing") $C L_{A}$, while the "neutral" setting is an intermediate point.

The employees on the manufacturing site involved in the experiment work both in a morning and the afternoon shift. During the morning shift the light setting changes from the "stimulating" setting to the "neutral" setting and during the afternoon shift it changes from the "stimulating" to the "relaxing" setting. The time and duration of the transitions had been chosen in a way to be able to provide enough stimulation for the circadian system to make it possible to do work with high performance as well as to simulate the natural change of the circadian effect of daylight to avoid the negative health impacts of the absence of natural light.

\section{On-site experiments}

During the experiments the luminaires had been tested in a real work environment with the participation of employees at an assembly line. During the experiments eight participants during both morning and afternoon shifts filled in questionnaires about their subjective preference of the lighting, and four participants had been wearing heartrate monitoring smartwatches which recorded the changes of their heartrate with 1-second resolution. Experimental data had been collected for two weeks using the human centric luminaires as local lighting, and for two weeks using a fixed spectrum LED tube local lighting.

\subsection{Heartrate monitoring and evaluation}

Heartrate is influenced by the circadian system (Rüger, Scheer, 2009) and can be recorded easily through extended periods of time using low-cost instruments. For these properties it had been chosen as the basis for objective evaluation of the effects on the circadian system. During the evaluation of the measurement results, the approximately 2-hours delay in the cardiovascular system's response to light stimuli had been taken into account by leaving two and a half hour windows as adaptation time between changing the light settings, and time correction of the calculation table. Measurement data of one day of three users had to be excluded from the analysis because of their excessive caffeine consumption on these specific days. The measurement noise of the sensors had to be removed from the results via a low-pass filter $(0,05 \mathrm{~Hz})$.

During the analysis the average heartrate measured under the active lighting cornerstones (and in the same intervals in case of the LED tube lighting) had been compared to the $C L_{A}$ and $\alpha-$ 
opic irradiances of the same light settings. Since these variables is considered in statistics "high measurement level" variables, Pearson correlation had been used.

Table 3 - Correlations between heartrate and the metrics used to describe non-visual responses to light

\begin{tabular}{|l|c|c|c|c|c|c|}
\hline & $C L_{A}$ & $\begin{array}{c}\text { S-cone-opic } \\
\text { irradiance }\end{array}$ & $\begin{array}{c}\text { M-cone-opic } \\
\text { irradiance }\end{array}$ & $\begin{array}{c}\text { L-cone-opic } \\
\text { irradiance }\end{array}$ & $\begin{array}{c}\text { Rhodopic } \\
\text { irradiance }\end{array}$ & $\begin{array}{c}\text { Melanopic } \\
\text { irradiance }\end{array}$ \\
\hline $\begin{array}{l}\text { Pearson } \\
\text { correlation }\end{array}$ & 0,437 & 0,504 & 0,533 & 0,534 & 0,525 & 0,520 \\
\hline $\begin{array}{l}\text { Significance } \\
\text { level }\end{array}$ & 0,010 & 0,002 & 0,001 & 0,001 & 0,001 & 0,002 \\
\hline
\end{tabular}

All of these tests resulted in significant, moderate positive correlations. These results can be interpreted in a way that in case of the LED tubes, the circadian effect was constant, and the heartrate too was nearly constant, but in case of the HCL prototypes, heartrate increased under the stimulating, and decreased under the relaxing settings. The explanation for the moderate strength of the correlation is that heartrate is affected by many other factors as well besides the circadian effect, for example movement around the workstation.

It can be also noted, that the correlation coefficients are higher in case of all $\alpha$-opic irradiances than in case of $C L_{A}$. The fact that $C L-$ and $C L_{A}$ aims to model melatonin suppression alone gives an explanation for this: it does not include other biological responses which might also influence heartrate as a consequence of exposure to a light stimulus, while the other metrics describe direct responses of retinal photoreceptors.

\subsection{Questionnaires}

The method for subjective assessment of the workers' opinion on the lighting had been done via questionnaires. These had to be filled at the start and at the end of the shifts and in the breaks. Two different questionnaires were used for the morning and the afternoon shifts with slightly different questions. On the questionnaires the questions were ordered into blocks which had to be filled during the breaks, or before or after work. In every block of questions there was an additional question about coffee and energy drink consumption. All except this question had to be marked on a four-level scale.

\section{Table 4 - Questions at the beginning of the shifts}

\begin{tabular}{|c|c|c|c|}
\hline \multicolumn{4}{|c|}{ How easily could you fall asleep after the previous workday? } \\
\hline Very hardly & Hardly & Easily & Very easily \\
\hline \multicolumn{4}{|c|}{ How would you evaluate the quality of sleep? } \\
\hline Very bad & Bad & Good & Very good \\
\hline
\end{tabular}

Table 5 - Questions during the shifts: repeated two times in case of the morning shift, three times during the afternoon shift

\begin{tabular}{|c|c|c|c|}
\hline \multicolumn{4}{|c|}{ Does the lighting cause glare? How disturbing is it during work? } \\
\hline $\begin{array}{c}\text { Yes, it makes } \\
\text { impossible to work }\end{array}$ & Yes, it is disturbing & $\begin{array}{c}\text { Only a bit, not } \\
\text { disturbing }\end{array}$ & Not at all \\
\hline \multicolumn{3}{|c|}{ How relaxing do you think the light is in the second half of the shift? } \\
\hline $\begin{array}{c}\text { Absolutely } \\
\text { stimulating }\end{array}$ & Rather stimulating & A bit relaxing & Very relaxing \\
\hline How well can you concentrate during the second half of the shift? \\
\hline \multicolumn{2}{|c|}{ Poorly } & Easily & Very easily \\
\hline
\end{tabular}


Table 6 - Questions at the end of the shifts

Did you notice unwanted shadows during work? If yes, how disturbing was the shadow?

\begin{tabular}{|c|c|c|c|}
\hline $\begin{array}{c}\text { Yes, it makes } \\
\text { impossible to work }\end{array}$ & Yes, a bit disturbing & $\begin{array}{c}\text { Yes, but not really } \\
\text { disturbing }\end{array}$ & No \\
\hline \multicolumn{4}{|c|}{ How tired do you feel at the end of the shift? } \\
\hline Extremely & A bit tired & Not really tired & Absolutely not tired \\
\hline
\end{tabular}

The encoded answers of the questions (encoded to integer numbers according to the four-level scale) became the variables of the statistical evaluation. Since these variables are considered "low measurement level variables" in statistics, Spearman correlation had been used to search for connections between the different variables.

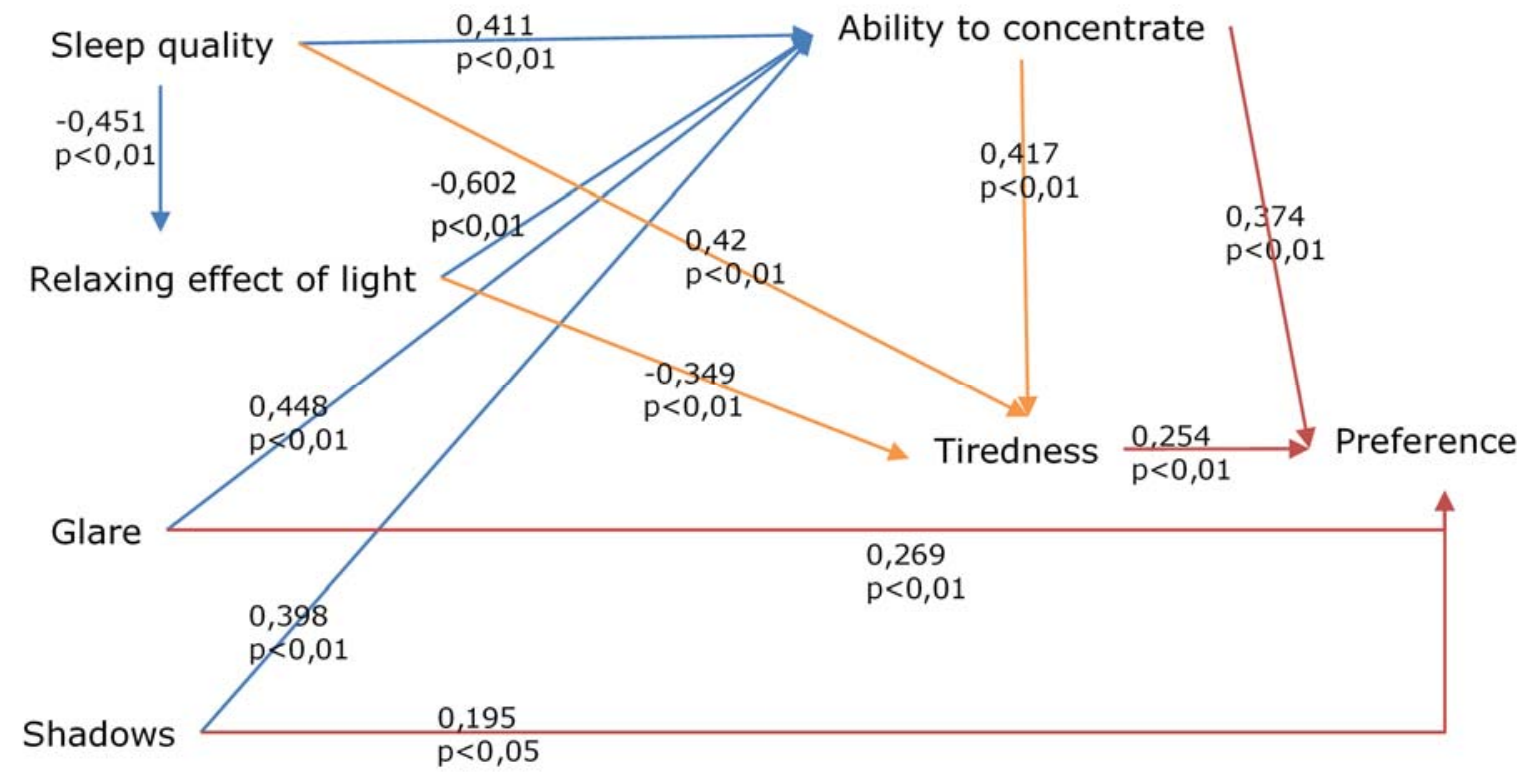

Figure 2 - Graph representation of notable correlations between the variables of the questionnaires' analysis

During the analysis a series of significant correlations had been found (Figure 2). In terms of preference, correlation with the perceived ability to concentrate, tiredness at the end of the shift, glare, and the presence of disturbing shadows were relevant. The participants preferred it more when their ability to concentrate was better and they were less tired at the end of the shift. Another correlation had been found directly between these two variables: participants felt less tired when they could concentrate better. Weak, but significant correlations had been found directly between the preference, glaring and the presence of disturbing shadows. The two latter variables were connected with moderate correlations to the perceived ability to concentrate. All other variables had a significant correlation with the users' perceived ability to concentrate. From the results it could be deduced that the participants could concentrate better if their sleep during the previous night was better, under stimulating lighting and when glare and the presence of shadows on the work area was minimal. It can also be noted, that there was a significant, moderate negative correlation between sleep quality and the perceived relaxing effect of light: participants perceived all lighting conditions less stimulating if their sleep quality was worse during the previous night.

Though there was no direct connection between preference and lighting system, the results suggest that the participants preferred the more stimulating light settings. Both their perceived ability to concentrate and tiredness at the end of the shift was in correlation with the light's perceived relaxing effect, and both of these parameters were in connection with preference. 


\section{Conclusion}

The aim of the study was to investigate the effects of human centric lighting on industrial workers through heartrate monitoring and questionnaires. Both experimental methods had been repeated in two phases each lasting for two weeks; using custom human centric luminaires and common LED tube luminaires as local lighting. The results had been analysed using statistical methods. The recorded heartrate had been compared to different metrics describing the ipRGC influenced responses to light: $C L_{\mathrm{A}}$, and $\alpha$-opic irradiances of the CIE S026:2018 standard. In each case the results were significant, moderate positive correlations. The statistical analysis of the questionnaire answers resulted in a series of correlations between the different variables. The most notable was the correlation between the perceived relaxing effect of the light and the ability to concentrate (coefficient: $-0,602$ ) and between the ability to concentrate and the preference of lighting (coefficient: 0,374). However direct connection between the lighting system and preference could not be shown, this suggests that the participants preferred the light settings where the lighting had a more stimulating effect. From both the heartrate monitoring experiments and the results of the questionnaires it can be concluded that the prototype luminaires set up on-site had indeed had an effect on the participants of the experiments.

\section{Acknowledgement}

The research had been funded by the "Light Quality Improvement for Supporting Health and Quality of Life" project, grant number: GINOP-2.2.1-15-2017-00095.

\section{References}

BELliA, L, PEDACE, A, BARBATO, G, 2014. Winter and summer analysis of daylight characteristics in offices. Building and Environment, 81, 150-161.

BERSON, DM, 2003. Strange vision: ganglion cells as circadian photoreceptors. Trends in Neurosciences, 26(6), 314-20.

BRAINARD, GC, HANIFIN, JP, GREESON, JM, BYRNE, B, GLICKMAN, G, GERNER, E, ROLLAG, MD, 2001. Action spectrum for melatonin regulation in humans: Evidence for a novel circadian photoreceptor. Journal of Neuroscience, 21, 6405-6412.

CHANG, AM, AESCHBACH, D, DUFFY, JF, CZEISLER, CA, 2015. Evening use of light emitting eReaders negatively affects sleep, circadian timing, and next morning alertness. Proceedings of the National Academy of Sciences, 112, 1232-1237.

CIE 2018. CIE S026:2018. CIE System for Metrology of Optical Radiation for ipRGC-Influenced Responses to Light. Vienna: CIE.

FIGUEIRO, M, OVERINGTON, D, 2015. Self-luminous devices and melatonin suppression in adolescent. Lighting Research and Technology, 2015 0, 1-10.

REA, MS, FIGUREIO, MG, BIERMAN, A, BULLOUGH, JD, 2010. Circadian light. Journal of Circadian Rhythms, 8, p.Art. 2.

RÜGER, M, SCHEER, FA, 2009. Effects of circadian disruption on the cardiometabolic system. Reviews in endocrine \& metabolic disorders, 10(4), 245-260. 